\title{
Vantagens de jogar em casa: uma análise de campeonatos estaduais da região nordeste
}

A vantagem de se disputar um campeonato em casa já é tema de estudo no mundo do esporte, tal fato é composto de inúmeros fatores, dentre eles se destacam a familiaridade com o espaço onde será realizado a disputa, o tempo de deslocamento da equipe visitante, o efeito da torcida nas decisões dos árbitros e os fatores psicológicos. Desta forma o objetivo do presente estudo é analisar se houve vantagem em jogar em casa nos campeonatos estaduais do Nordeste em 2019, através de um estudo do tipo documental com abordagem quantitativa, no qual foram analisados as vitórias, derrotas e empates das 333 partidas, juntando as partidas de todos os 9 (noves), campeonatos estaduais do nordeste da série A em 2019 . Os resultados desse estudo mostram que somente $33,3 \%$ dos estados do estudo tiveram maior percentual de vitória quando o jogo foi realizado em casa onde a Paraíba foi o estado nordestino com maior percentual de vitórias nos campeonatos em que jogou em casa, quando comparado aos demais, enquanto que $66,7 \%$ tiveram maior percentual de derrota. Sergipe caracterizou-se como o estado do Nordeste que obteve maior quantidade de derrotas ao invés de vitórias, quando os campeonatos ocorreram no próprio estado. Nessa situação, constata-se, a partir deste estudo, que há uma tendência de redução da vantagem de 'jogar em casa'. O estudo permitiu verificar que o fator 'jogar em casa' não influencia de forma direta na vitória, o que pode ser apresentado pelo fato dos jogadores ficarem mais confiantes. Dessa forma, o fato de jogar em casa apresentar vantagem, não parece demonstrar regularidade tendo em vista que os dados expostos revelam que no Nordeste, a maioria dos estados teve maior percentual de derrota, ao invés de vitória, quando os campeonatos foram realizados nos próprios estados. Notoriamente, há a necessidade de se desenvolver um corpo de pesquisa mais sólido a respeito, realizar estudos que possam se aprofundar nas inúmeras questões pertinentes ao fenômeno.

Palavras-chave: Esporte; Futebol; Aspectos Psicológicos.

\section{Advantages of playing at home: an analysis of state championships in the northeast region}

\begin{abstract}
The advantage of playing in a championship at home is already a subject of study in the world of sport. This fact is composed of numerous factors, among which stand out the familiarity with the space where the dispute will take place, the traveling time of the visiting team, the effect of the crowd on the decisions of the referees and the psychological factors. Thus, the objective of the present study is to analyze whether there was an advantage in playing at home in the Northeast state championships in 2019, through a documentary type study with a quantitative approach, in which the victories, defeats and draws of the 333 matches were analyzed, joining the matches of all 9 (nines), state championships in the northeast of series A in 2019. The results of this study show that only $33.3 \%$ of the states in the study had a higher percentage of victory when the game was played at home where Paraiba was the northeastern state with results of this study show that only $33.3 \%$ of the states in the study had a higher percentage of victory when the game was played at home where Paraiba was the northeastern state with
the highest percentage of victories in the championships in which it played at home, when compared to the others, while $66.7 \%$ had the highest percentage of defeat. Sergipe was the highest percentage of victories in the championships in which it played at home, when compared to the others, while $66.7 \%$ had the highest percentage of defeat. Sergipe was
characterized as the state of the Northeast that had the highest number of defeats instead of victories, when the championships took place in the state itself. In this situation, it appears from characterized as the state of the Northeast that had the highest number of defeats instead of victories, when the championships took place in the state itself. In this situation, it appears from
this study that there is a tendency to reduce the advantage of 'playing at home'. The study showed that the factor 'playing at home' does not directly influence victory, which can be shown by the fact that players are more confident. Thus, the fact that playing at home presents an advantage, does not seem to demonstrate regularity, given that the data exposed reveal that in the Northeast, most states had a higher percentage of defeat, rather than victory, when the championships were held in their own country. States. Notoriously, there is a need to develop a more solid body of research on this subject, to carry out studies that can deepen the innumerable issues pertinent to the phenomenon.
\end{abstract}

Keywords: Sport; Soccer; Psychological aspects.

Topic: Práticas Esportivas e de Lazer

Reviewed anonymously in the process of blind peer.
Received: 05/01/2020

Approved: 22/04/2020
Marcos Antônio Araújo Bezerra (iD)

Centro Universitário Dr. Leão Sampaio, Brasil http://lattes.cnpq.br/4643352879633283 http://orcid.org/0000-0002-3385-4024

marcosantonio@leaosampaio.edu.br

Vanessa Guedes Silva (iD

Centro Universitário Vale do Salgado, Brasil http://lattes.cnpq.br/2318161018642801 http://orcid.org/0000-0003-2741-9760 vanessaguedes159@gmail.com

Gabriela Gomes de Oliveira Bezerra (ii) Centro Universitário Dr. Leão Sampaio, Brasil http://lattes.cnpq.br/6330341118187369 http://orcid.org/0000-0002-9724-708X gabriela.o.bezerra@gmail.com

d

DOI: 10.6008/CBPC2674-6654.2020.001.0004
José de Caldas Simões Neto (iD

Centro Universitário Dr. Leão Sampaio, Brasil

http://lattes.cnpq.br/0470733825644726 http://orcid.org/0000-0003-1036-2315

josecaldas@leaosampaio.edu.br

Renan Costa Vanali (iD

Centro Universitário Dr. Leão Sampaio, Brasil

http://lattes.cnpq.br/0464534899158947

http://orcid.org/0000-0002-4193-3363

renan@leaosampaio.edu.br

Referencing this:

BEZERRA, M. A. A.; SILVA, V. G.; BEZERRA, G. G. O.; SIMÕES NETO, J. C.; VANALI, R. C.. Vantagens de jogar em casa: uma análise de campeonatos estaduais da região nordeste. Humanum Sciences, v.2, n.1, p.25-29, 2019. DOI: http://doi.org/10.6008/CBPC2674$\underline{6654.2020 .001 .0004}$ 


\section{INTRODUÇÃO}

A vantagem de se disputar um campeonato em casa já é tema de estudo no mundo do esporte, Barreira (2018) aponta em seu estudo que de fato essa vantagem existe, e é composta de inúmeros fatores, dentre eles destacam-se a familiaridade com o espaço onde será realizado a disputa, o tempo de deslocamento da equipe visitante, o efeito da torcida nas decisões dos árbitros e os fatores psicológicos. Quanto aos fatores psicológicos cabe salientar que afetam diretamente no desempenho do atleta na competição.

Brandt et al. (2015) atesta essa assertiva em seu estudo, e salienta que o atleta ao ser exposto ao ambiente competitivo passa por mudanças de humor, sejam elas negativas (tensão, depressão, raiva, fadiga e confusão) ou positiva (vigor), alteram a forma como o mesmo realizará suas tarefas no momento do jogo, refletindo no seu comportamento, pensamento, estado emocional e estado corporal.

A vantagem de jogar em casa vem demonstrando-se constante em diversos campeonatos sejam eles: estaduais, nacionais e até mesmo, em ligas europeias, e em diversos esportes sejam eles coletivos ou não. Nas competições atuais, por volta de 60 a $65 \%$ dos pontos obtidos são em casas, esses valores correspondem a campeonatos em todo mundo, incluindo o esporte brasileiro (SILVA et al., 2012)

Dentre os fatores já citados Nevill et al. (2012) destaca dados relevantes quanto ao efeito da torcida sobre decisão dos árbitros, em seu estudo ele apresenta uma comparação dos números de faltas marcadas em uma partida assistida pelos árbitros com o barulho da torcida e sem a influência do barulho. Com a influência do barulho os árbitros marcaram 15,5\% menos faltas para o time da casa.

Em detrimento supracitado cabe ressaltar que a capacidade técnica das equipes em disputa ainda é o maior fator de relevância para a obtenção da vitória competição, contudo os demais fatores que rodeiam a obtenção dessas vitórias não podem ser ignorados. Jogar em casa é estudado como um fator que influencia diretamente no andamento da partida e consequentemente tem sua parcela de influência no resultado final (SANTOS et al., 2016). Desta forma o objetivo do presente estudo é analisar se houve vantagem jogar em casa nos campeonatos estaduais do Nordeste em 2019.

\section{METODOLOGIA}

Trata-se de um estudo do tipo documental com abordagem quantitativa, no qual foram analisados as vitórias, derrotas e empates das 333 partidas, juntando as partidas de todos os 9 (noves), campeonatos estaduais do nordeste da série A em 2019. Sendo 52 partidas do Campeonato Pernambucano, 29 do Campeonato de Potiguar, 34 do Campeonato Maranhense, 25 do Campeonato Paraibano, 30 do Campeonato Piauiense, 32 do Campeonato Sergipano, 36 do Campeonato Alagoano, 34 do Campeonato Baiano e 61 do Campeonato Cearense. Serviram para analise os resultados de cada jogo das competições.

Para a aquisição dos dados de coleta, o pesquisador acessou os sites das federações respectivas de futebol, onde estão disponíveis para download as sumulas de todas as partidas da competição. Para tabulação dos dados, as vitórias, derrotas e empates de cada jogo. Todas as análises estatísticas foram 
realizadas através do SPSS for Windows (versão 23.0, SPSS), por meio de estatística descritiva por distribuição de frequência.

\section{RESULTADOS E DISCUSSÃO}

Para a verificação dos fatores da vantagem de jogar em casa nos campeonatos estaduais da Região Nordeste foram analisados as vitórias e derrotas de 333 jogos, dos nove campeonatos da série A em 2019 e os dados concernentes à temática foram estruturados através de tabelas para facilitar a análise.

Os resultados desse estudo mostram que o fenômeno da vantagem de jogar em casa foi comprovado apenas em três estados nordestinos apresentado índices de vitória maiores que de derrotas como expõem os dados na tabela 1, onde a Paraíba foi o estado nordestino com maior percentual de vitórias nos campeonatos em que jogou em casa, quando comparado aos demais. O segundo estado com maior percentual de vitórias foi o Pernambuco, seguido do Estado de Alagoas.

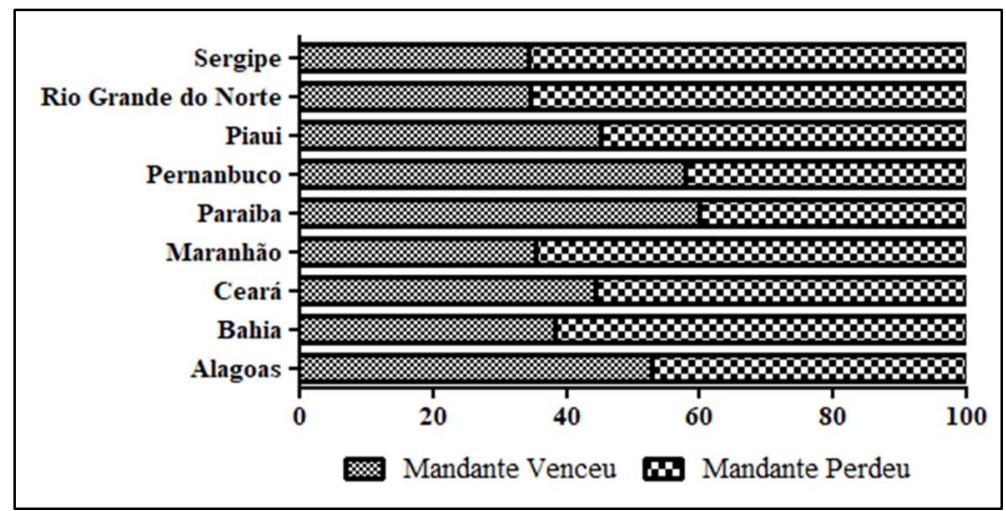

Figura 1: Distribuição de vitorias e derrotas das equipes mandantes nos campeonatos estaduais de futebol da região nordeste, 2019.

O percentual de vitorias dos mandantes foi: Pernambucano (57.7\%), Rio Grande do Norte (34.5\%), Maranhense (35.3\%), Paraibano (60.0\%), Piauiense (45\%), Sergipano (34.4\%), Alagoano (52.8\%), Baiano (38.2\%), Cearense (44.3\%). Com base na tabela somente $33,3 \%$ dos estados do estudo tiveram maior percentual de vitória quando o jogo foi realizado em casa, enquanto os demais $66,7 \%$ tiveram maior percentual de derrota. Sergipe caracterizou-se como o estado do Nordeste que obteve maior quantidade de derrotas ao invés de vitórias, quando os campeonatos ocorreram no próprio estado sendo seguido pelos Estado de Rio Grande do Norte, Maranhão, Bahia, Ceará e Piauí.

Esses dados corroboram com o estudo de Fontes (2007), onde apresenta que quando os competidores jogam em casa, possuem maior confiança, ficam menos preocupados com os adversários, entretanto, com maior pressão, estresse, ansiedade e maior diversão. A pressão ocorre pelo fato desses jogadores conhecerem o local em que competirão, estando assim mais familiarizados, e essa pressão é imposta tanto por eles mesmos, quanto pelo público.

Nessa situação, constata-se, a partir deste estudo, que há uma tendência de redução da vantagem de 'jogar em casa'. Nas últimas décadas o futebol passou por profundas mudanças, quer seja no aspecto tático, físico ou técnico trazendo muito equilíbrio entre as equipes e que podem contrariar resistência a esta 
citada vantagem, havendo assim, uma tendência de melhoria no desempenho das equipes quando elas jogam "fora de casa" (MASCARA, 2011).

Quando a vantagem de "jogar em casa" não sobressai e/ou é anulada pelos adversários, ocorre um forte equilibro competitivo entre as equipes, e a partir daí o que se segue é a tendência do futebol moderno, em que os detalhes eventuais podem estar decidindo muitas partidas. Estes detalhes estão nas esferas físicas, técnicas, táticas e psicológicas, sendo que as duas últimas e com suas diversas inter-relações, têm apresentado um peso especial ultimamente, e é onde os técnicos podem buscar um diferencial competitivo para suas equipes (PINTO et al., 2008).

É notório que jogar em casa representa uma enorme responsabilidade para a equipe anfitriã, já que frente ao seu próprio público é necessário dar tudo de si, para satisfazer expectativa e honrar o nome do clube. Esse maior encargo pode envolver o psicológico dos atletas, pois os times que jogam em casa precisam fazer gols, mas ao mesmo tempo ficam receosos de saírem para o ataque para não ceder ao adversário o gol fora de casa (SILVA et al., 2008).

Por tanto quem joga fora de casa, por sua vez, joga mais confortável e assim mantém o foco e a concentração por saber que os contra-ataques estarão à disposição. Com isso é importante que cada equipe conheça suas forças e limitações tanto dentro quanto fora de casa para traçar estratégias que possam melhorar seu desempenho geral, afinal o objetivo é o mesmo e três pontos em casa valem a mesma coisa do que três pontos fora, assim cabe a cada equipe dar o melhor de si (DRUMMOND et al., 2014).

Fontes (2007) destaca que "o desempenho na casa do adversário influencia diretamente na disputa pela corrida de um campeonato" Assim, percebe-se que jogar em casa influência nos resultados do futebol, tendo em vista que há diferenças comportamentais, pois os que jogam em casa apresentam maior agressividade, com maior tensão, enquanto os que jogam fora de casa geralmente jogam por diversão, o que contribui para o alcance de resultados positivos (FONTES, 2007).

Isso pode, então, contribuir para a diminuição dos resultados e explicar o porquê dos dados de estudo. Quanto aos estados que apresentaram maiores índices de vitória do que derrota corrobora com os dados do autor, que mostra que a persistência para jogadores que estão em casa é muito maior quando estão jogados em outros lugares, buscando assim melhorarem as suas estratégias e desenvolvendo as suas aptidões técnicas, tendo em vista que há fatores, como o deslocamento de um local para outro, que pode interferir nos resultados (BARREIRA, 2018).

Vale ressaltar que quando leva em consideração a qualidade das equipes analisadas provavelmente o time de melhor desempenho ganhe o jogo, jogando em casa ou não, o importante é manter o foco e adaptar-se as diversas circunstancias do jogo, pois o time que quer ser campeão não se preocupa em ficar escolhendo em que local deve jogar, seu dever é entrar em campo e vencer, independentemente do jogo (ALMEIDA et al., 2011).

Diante do exposto fica claro que as probabilidades de cada resultado em cada jogo dependem de muitos fatores, impossíveis de se levar em conta nos mínimos detalhes. Como exemplos, o estádio onde é disputada a partida, a participação da torcida, a temperatura no horário do jogo, se chove ou não, os 
desfalques de cada equipe, os resultados recentes dos times, a situação de cada um no campeonato, o árbitro escalado para o confronto entre outros. E embora todos esses aspectos sejam validos, é de esperar que o grau de interferência e de integração de todos eles estejam atrelados a qualidade dos clubes, criando sinergia e obtendo o melhor de cada um a fim de superar os resultados desejados.

\section{CONCLUSÕES}

Conclui-se que na Região do Nordeste o percentual de vitórias nos jogos em casa foi menor do que o percentual de derrotas. $O$ estudo permitiu verificar que o fator 'jogar em casa' não influencia de forma direta na vitória, o que pode ser apresentado pelo fato dos jogadores ficam mais confiantes. Dessa forma, o fato de jogar em casa apresentar vantagem, não parece apresentar regularidade tendo em vista que os dados mostrados revelam que no Nordeste, a maioria dos estados teve maior percentual de derrota, ao invés de vitória, quando os campeonatos foram realizados nos próprios estados. Notoriamente, há a necessidade de se desenvolver um corpo de pesquisa mais sólido a respeito, realizar estudos que possam se aprofundar nas inúmeras questões pertinentes ao fenômeno.

\section{REFERÊNCIAS}

ALMEIDA, L. G.; OLIVEIRA, M. L.; SILVA, C. D.. Uma análise da vantagem de jogar em casa nas duas principais divisões do futebol profissional brasileiro. Revista Brasileira de Educação Física e Esporte, v.25, n.1, p.49-54, 2011.

BARREIRA, J.. Vantagem de jogar em casa no futebol feminino: uma análise dos três principais campeonatos no Brasil. R. bras. Ci. e Mov., v.26, n.3, p.83-87, 2018.

BRANDT, R.; HOBOLD, E.; VIANA, M. S.; DOMINSKI, F. H.; BEVILACQUA, G. G.; TURCZYN, B.. Humor pré-competitivo em atletas brasileiros de jiu-jitsu. Caderno de Educação Física e Esporte, v.13, n.1, p.21-30, 2015.

DRUMMOND, L. R.; DRUMMOND, F. R.; SILVA, C. D.. A vantagem em casa no futebol: comparação entre Copa Libertadores da América e UEFA Champions League. Revista Brasileira de Educação Física e Esporte, v.28, n.2, p.283-292, 2014.

FONTES, I. G. M.. O 'fator casa' no Futebol. Monografia (Licenciatura em Educação Física) - Universidade de Porto, Porto, 2007.

MASCARA, D. I.; CARVALHO, D. M.; CHIMINAZZO, J. G. C. Vantagem de jogar em casa no campeonato paulista de futebol. In: CONGRESSO BRASILEIRO DE CIÊNCIAS DO FUTEBOL, 4. Anais. 2011.
NEVILL, A. M.; BALMER, N. J.; WILLIAMS, A. M.. The influence of crowd noise and experience upon refereeing decisions in football. Psychol Sport Exerc., v.3, n.4, p.261-272, 2012.

PINTO, F. P.; COLEDAM, D. H. C.; SANTOS, J. W.. Comparação da vantagem de 'jogar em casa' nos campeonatos nacionais brasileiro, espanhol, inglês e italiano da primeira divisão na temporada de 2007. Revista Motriz, Rio Claro, v.14, n.2, p.S1-S141, 2008

SANTOS, A. A. S.; CARDOSO, F. S. L.; ANDRADE, M. O. C.; AÑON, I. C.; COSTA, I. T.. Jogar em casa pode condicionar o resultado final do jogo?. Rev. Bras. Futebol, Viçosa, v.9, n.2, p.87-97, 2016.

SILVA, C. D.; MOREIRA, D. G.. A vantagem em casa no futebol: comparação entre o Campeonato Brasileiro e as principais ligas nacionais do mundo. Rev. Bras.

Cineantropom Desempenho Hum., v.10, n.2, p.184-188, 2008.

SILVA, C. D.; MEDEIROS, N. C.; SILVA, A. C. D.. Vantagem em casa no campeonato brasileiro de futebol: efeito do local do jogo e da qualidade dos times. Revista Brasileira de Cineantropometria \& Desempenho Humano, v.2, n.12, p.148-154, 2012

A CBPC - Companhia Brasileira de Produção Científica (CNPJ: 11.221.422/0001-03) detém os direitos materiais desta publicação. Os direitos referem-se à publicação do trabalho em qualquer parte do mundo, incluindo os direitos às renovações, expansões e disseminações da contribuição, bem como outros direitos subsidiários. Todos os trabalhos publicados eletronicamente poderão posteriormente ser publicados em coletâneas impressas sob coordenação da Sapientiae Publishing, da Companhia Brasileira de Produção Científica e seus parceiros autorizados. Os (as) autores (as) preservam os direitos autorais, mas não têm permissão para a publicação da contribuição em outro meio, impresso ou digital, em português ou em tradução. 